poisoning in the United Kingdom: before and after study. BMJ 2001;322:1203-7.

2 Khashab M, Tector AJ, Kwo PY. Epidemiology of acute liver failure. Curr Gastroenterol Rep 2007;9:66-73.

3 Davidson DG, Eastham WN. Acute liver necrosis following overdose of paracetamol. BMJ 1966;2: 497-9.

4 Thomson JS, Prescott LF. Liver damage and impaired glucose tolerance after paracetamol overdosage. BMJ 1966;2:506-7.

5 Vale A. Paracetamol (acetaminophen). Medicine 2007 (in press).

6 Bernal W, Donaldson N, Wyncoll D, Wendon J. Blood lactate as an early predictor of outcome in paracetamolinduced acute liver failure: a cohort study. Lancet 2002;359:558-63.

7 Pakravan N, Bateman DN, Goddard J. Effect of acute paracetamol overdose on changes in serum and urine electrolytes. Br J Clin Pharmacol 2007;64:824-32.

8 Vale JA, Proudfoot AT. Paracetamol (acetaminophen) poisoning. Lancet 1995; 346:547-52.

9 O'Grady JG, Wendon J, Tan KC et al. Liver transplantation after paracetamol overdose. BMJ 1991;303:221-3.

10 Seifert SA, Bronstein AC, McGuire T. Massive ibuprofen ingestion with survival. J Toxicol Clin Toxicol 2000;38:55-7.

11 Smolinske SC, Hall AH, Vandenberg SA, Spoerke DG, McBride PV. Toxic effects of nonsteroidal anti-inflammatory drugs in overdose. An overview of recent evidence on clinical effects and dose-response relationships. Drug Saf 1990;5:252-74.

12 Goddard J, Stachan FE, Bateman DN. Urinary sodium and potassium excretion as measures of ibuprofen nephrotoxicity. J Clin Toxicol 2003;41:747.

13 Flomenbaum NE. Salicylates. In: Flomenbaum NE, Howland MA, Hoffman RS. Goldfrank's toxicologic emergencies, 8th edn. London: McGraw-Hill Professional, 2006.

14 Afshari R, Good AM, Maxwell SR, Bateman DN. Co-proxamol overdose is associated with a 10 -fold excess mortality compared with other paracetamol combination analgesics. Br J Clin Pharmacol 2005;60:444-7.

\section{Recreational drug}

\section{toxicity}

Simon Hill ${ }^{1}$ MRCP, Specialist Registrar in Clinical Pharmacology and Therapeutics

Simon HL Thomas ${ }^{1,2}$ MD FRCP FRCPE, Consultant Physician and Reader in Therapeutics

${ }^{1}$ Newcastle upon Tyne Hospitals NHS

Foundation Trust

${ }^{2}$ Newcastle University

Clin Med 2008;8:99-103

\section{Introduction}

In $2005-6,10.5 \%$ of people aged 16-59 years who lived in England and Wales had used at least one illicit drug in the previous year and $3.4 \%$ had used a class $\mathrm{A}$ drug (Table 1), so it is not surprising that presentations to hospital with toxicity are common. ${ }^{1}$ The age-standardised mortality associated with drug misuse increased between 1993 and 2000 but has declined since then. Most deaths involve men and people who are using opioids/opiates, especially heroin, methadone and dihydrocodeine, but deaths associated with cocaine and codeine have been increasing (Fig 1). ${ }^{2}$ Recreational drug toxicity occurs in the context of other health and social probfor example, social and criminal justice issues, mental health problems and alcohol and tobacco abuse, as well as bloodborne virus infection, thrombosis and infections in intravenous users.

\section{Cannabis}

Smoking or ingestion of cannabis, which is derived from the plant Cannabis sativa, is common, but it is unusual for users to require hospital treatment. They occasionally present with disorientation, anxiety or tachycardia, and arrhythmias such as atrial fibrillation have been reported. Long-term use has been connected with psychosis and chronic lung disease. ${ }^{3}$

\section{Stimulants}

Sympathomimetic amines - for example, amfetamines, ecstasy, piperazines and cocaine - act by enhancing central release and inhibiting reuptake and metabolism of catecholamines and serotonin. This results in increased concentrations of norepinephrine, epinephrine, dopamine or serotonin, or their combination, within the synaptic cleft.

These substances share a number of clinical effects, although their precise mode of action and potency for causing each differs. The effects produced lems that may also need to be addressed -

\section{Key Points}

Toxicity associated with recreational drug use is a common reason for presentation to hospital

Most deaths are associated with heroin, methadone, benzodiazepines and cocaine. Deaths due to cocaine are increasing in the UK

Stimulants (for example, amfetamines and cocaine) have adrenergic effects. Serious complications of toxicity are most common with cocaine and include metabolic acidosis, convulsions, rhabdomyolysis, myocardial infarction and stroke

Toxicity from opiates and opioids is exacerbated by co-ingestion of alcohol and other sedatives and those with recent abstinence. Opioid effects can be reversed by the competitive antagonist naloxone

Treatment of benzodiazepine toxicity with the antidote flumezanil can increase the level of consciousness but may cause convulsions and acute benzodiazepine withdrawal

KEY WORDS: cocaine, ecstasy, gamma hydroxybutyrate, heroin, poisoning 
Table 1. Examples of potential drugs of misuse and their classification under UK Misuse of Drugs legislation.

\begin{tabular}{|c|c|c|c|c|}
\hline & & \multicolumn{3}{|c|}{ Class $^{2}$} \\
\hline & & A & B & C \\
\hline Schedule ${ }^{1}$ & & Most harmful & Intermediate & Least harmful \\
\hline 1 & $\begin{array}{l}\text { No recognised medical use Possession prohibited } \\
\text { without licence from Home Office }\end{array}$ & $\begin{array}{l}\text { Ecstasy } \\
\text { LSD }\end{array}$ & & Cannabis \\
\hline 2 & $\begin{array}{l}\text { Recognised medical use } \\
\text { Subject to special prescription and safe custody } \\
\text { requirements and the need to maintain registers }\end{array}$ & $\begin{array}{l}\text { Morphine } \\
\text { Diamorphine } \\
\text { Methadone } \\
\text { Cocaine }\end{array}$ & $\begin{array}{l}\text { Amfetamines } \\
\text { Methylamfetamine } \\
\text { Dihydrocodeine } \\
\text { Codeine }\end{array}$ & \\
\hline 3 & $\begin{array}{l}\text { Subject to special prescription although not to safe } \\
\text { custody requirements }\end{array}$ & & Barbiturates & $\begin{array}{l}\text { Temazepam } \\
\text { Flunitrazepam }\end{array}$ \\
\hline 4 (Part 1) & $\begin{array}{l}\text { Subject to neither special prescription nor safe custody } \\
\text { requirements }\end{array}$ & & & $\begin{array}{l}\text { Other benzodiazepines } \\
\text { Zolpidem } \\
\text { GHB } \\
\text { Ketamine }\end{array}$ \\
\hline 4 (Part 2) & & & & Anabolic steroids \\
\hline 5 & $\begin{array}{l}\text { Preparations that, because of their strength, are exempt } \\
\text { from most of the controlled drug requirements }\end{array}$ & & & $\begin{array}{l}\text { Cough medicines } \\
\text { Antidiarrhoeals }\end{array}$ \\
\hline
\end{tabular}

GHB = gamma hydroxybutyrate; LSD = lysergic acid diethylamide.

${ }^{1}$ Misuse of Drugs Regulations, 2001.

${ }^{2}$ Misuse of Drugs Act, 1971

include a feeling of wellbeing, increased energy, increased self-esteem and alertness. At higher doses, adrenergic effects, such as anxiety, sweating, tachycardia, hypertension and dilated pupils, are common. Subsequently, confusion, hallucinations, agitation, vomiting and abdominal pain may occur. Serious com-

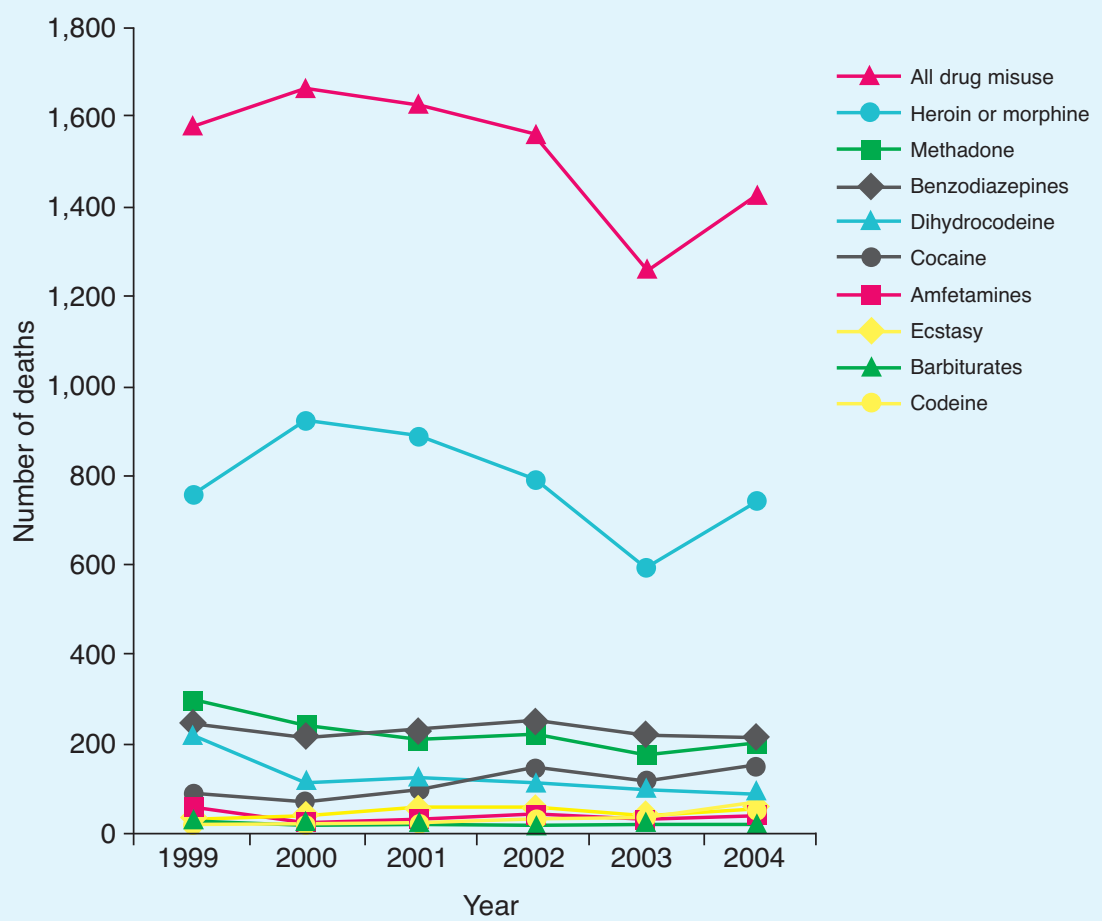

Fig 1. Number of deaths for some specific substances involved in deaths related to drug misuse, 1999-2004. Data sourced from Reference 2. plications include metabolic acidosis, tachyarrhythmias, convulsions, chest pain, hyperpyrexia, cerebral infarction or haemorrhage (Fig 2), rhabdomyolysis, disseminated intravascular coagulation, renal failure and myocardial infarction. ${ }^{4,5}$ Severe effects are more common after intravenous use or overdose.

Patients who present with toxicity should undergo cardiovascular and ECG monitoring. A 12-lead ECG should be performed and blood should be taken for measurement of electrolytes, bicarbonate and hepatic and renal function. Blood gases and creatinine kinase should be obtained when severe poisoning is suspected. Activated charcoal may reduce absorption after ingestion, but most patients present with established clinical effects, at which point this treatment is unlikely to affect outcome. Further management is directed at complications (Table 2).

\section{Amfetamines}

Recreational use of amfetamines is usually via ingestion, nasal inhalation of powder ('snorting') or injection. The 
latter two routes give more rapid and intense effects. There is considerable individual variation in response, and tolerance develops in habitual users. Use of methamphetamine has been increasing in some countries.

Adrenergic clinical effects are common and may be associated with increased appetite and headache. As these effects wear off, restlessness, fatigue and depression may ensue, which encourages the user to take further doses. Chronic use is associated with aggressive behaviour, delusions and paranoia ('amfetamine psychosis').

\section{Ecstasy}

Ecstasy (3,4 methylenedioxymethamphetamine (MDMA)) is a semi-synthetic amfetamine-like drug that is usually taken by ingestion. It increases central concentrations of serotonin and, to a lesser extent, dopamine. The half-life is about eight hours; clinical effects occur within about 20 minutes of ingestion and may last six hours or more. Ecstasy commonly causes adrenergic effects similar to, although generally less intense than, those seen with other sympathomimetic amines. Nausea and trismus are common.

Occasional patients may develop severe apparently idiosyncratic adverse

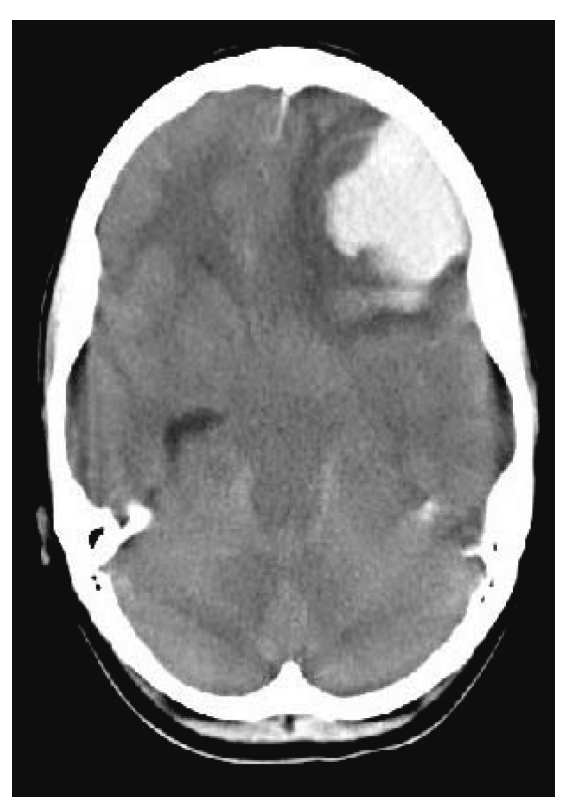

Fig 2. Intraparenchymal cerebral haemorrhage in an intravenous user of amphetamines.

Table 2. Complications and management of sympathomimetic amine toxicity.

\begin{tabular}{|c|c|}
\hline Complication & Notes on management \\
\hline $\begin{array}{l}\text { Confusion, behavioural } \\
\text { disturbances }\end{array}$ & Diazepam or lorazepam \\
\hline \multirow[t]{5}{*}{ Tachyarrhythmias } & Avoid treatment unless cardiovascular compromise \\
\hline & Correct $\mathrm{pH}$ and electrolytes \\
\hline & $\begin{array}{l}\text { Diazepam or lorazepam if supraventricular and associated with } \\
\text { agitation }\end{array}$ \\
\hline & $\begin{array}{l}\beta \text { blockade may be effective but risks hypertension due to } \\
\text { unopposed alpha stimulation }\end{array}$ \\
\hline & Calcium channel blockade may also be considered \\
\hline \multirow[t]{2}{*}{ Hypertension } & Diazepam or lorazepam. \\
\hline & $\begin{array}{l}\text { Consider infusion of glyceryl trinitrate (GTN) if } \\
\text { diazepam/lorazepam ineffective and hypertension is severe }\end{array}$ \\
\hline Seizures & Diazepam or lorazepam \\
\hline Acidosis & Correct with sodium bicarbonate \\
\hline \multirow[t]{2}{*}{ Hyperpyrexia } & Physical cooling methods \\
\hline & Consider dantrolene if cooling ineffective \\
\hline \multirow[t]{4}{*}{ Rhabdomyolysis } & Intravenous fluids \\
\hline & Urinary alkalinisation \\
\hline & Monitor renal function and potassium \\
\hline & Dialysis for renal failure or severe hyperkalaemia \\
\hline
\end{tabular}

effects, including fulminant hepatic failure, aplastic anaemia or a syndrome similar to neuroleptic malignant syndrome. Hyponatraemia may also occur because of inappropriate antidiuretic hormone action. This is worsened if users drink large amounts of fluids. ${ }^{6}$

Management is as for poisoning with other sympathomimetic amines. Hepatic failure should be treated conventionally. Liver transplantation has been performed successfully for patients with fulminant hepatic failure.

\section{Cocaine}

Cardiovascular complications are particularly common with cocaine and include arrhythmias, myocardial ischaemia or infarction, aortic or coronary dissection, ${ }^{7-9}$ intracerebral or subarachnoid haemorrhage and cerebral infarction. ${ }^{4}$ Management is supportive (Table 2). If adequate sedation or glyceryl trinitrate infusion fail to control hypertension, a calcium channel blocker may be effective. Ventricular arrhythmias may respond to lidocaine, but this should be used only once the $\mathrm{pH}$ has been corrected.

Chest pain may herald coronary ischaemia or infarction in cocaine intox- ication. Initial treatment should be with diazepam and nitrates. Aspirin and intravenous nitrates should be given to patients with features of ischaemia on ECG. Conventional thrombolysis should be considered if there are no contraindications. Troponin I should be measured after an appropriate interval.

Hyperpyrexia with cocaine may be life-threatening and must be treated aggressively - for example, using ice baths and possibly dantrolene.

\section{Piperazines}

A variety of piperazine-based recreational drugs are emerging, including benzylpiperazine, phenylpiperazine (trifluoromethylphenylpiperazine, TFMPP) and 1-(meta-chlorophenyl)piperazine (mCPP). These are usually taken as tablets, but intravenous use has occasionally been reported. These drugs stimulate release of dopamine and norepinephrine and inhibit reuptake of serotonin, dopamine and norepinephine. Clinical effects are similar, although usually less marked, than those of the amfetamines. Cerebral oedema and convulsions have been reported. ${ }^{10,11}$ Management is as for other sympathomimetics (Table 2). 


\section{Opiates and opioids}

Heroin (diacetylmorphine) is highly addictive. Although absorbed rapidly when taken by mouth, inhaled as a powder or smoked, serious toxicity is less common via these routes, and most deaths occur after intravenous injection. ${ }^{12}$ Methadone is widely available, and misuse is common, with effects similar to heroin but much more prolonged. In addition, the drug may cause delayed ventricular repolarisation, QT interval prolongation and torsade de pointes ventricular tachycardia. ${ }^{13}$ Life-threatening poisoning is well recognised after oral ingestion. Oxycodone can also produce prolonged and severe toxic effects. Illicit use of codeine, dihydrocodeine and tramadol is also common, but these are less potent agents and serious poisoning is uncommon unless large doses are taken. Abuse of dextropropoxyphene, as a constituent of co-proxamol, is becoming less common now that this preparation is being phased out.

Characteristic clinical features of intoxication include nausea, vomiting, confusion and hallucinations, which progress to miosis, hypotension, tachycardia, central nervous system and respiratory depression or arrest. Rhabdomyolysis, renal failure, aspiration pneumonia and noncardiac pulmonary oedema may occur. The presence of needle tracks may be a clue as to aetiology in a patient who presents with unconsciousness. Lifethreatening intoxication is more common after a period of abstinence (for example, after release from prison) and with coingestion of sedatives, including alcohol and/or benzodiazepines. ${ }^{12}$

The short-acting, lipid-soluble, competitive opiate receptor antagonist naloxone penetrates the central nervous system rapidly to reverse the features of toxicity after intravenous injection. It may also be given effectively via the intramuscular or subcutaneous routes. The aim of naloxone treatment is to ensure that the patient is sufficiently conscious to maintain their airway and ventilation, and doses should be titrated carefully to achieve this. Although substantial doses may be required for seriously poisoned patients, excessive doses may precipitate acute withdrawal syndromes associated with confusion or aggression. Patients may then leave hospital and subsequently develop recurrent opiate toxicity. Patients should not be discharged from hospital until at least six hours after the last dose of naloxone is given. Other reported adverse effects of naloxone are seizures, pulmonary oedema and arrhythmias, although these seem to be uncommon. ${ }^{12}$

Pending treatment with naloxone, patients should be given supportive management including adequate oxygenation and attention to the airway. Before and after naloxone treatment, frequent monitoring of the pulse, blood pressure, oxygen saturation and level of consciousness should be performed. Otherwise, treatment is supportive and symptomatic

\section{Benzodiazepines}

Benzodiazepines, including diazepam and temazepam, are commonly misused and frequently implicated in intentional or accidental poisoning. Clinical effects include drowsiness, unsteadiness, nystagmus and slurred speech. Coma associated with reduced tendon reflexes may occur, especially in those with underlying respiratory or neurological disease or when alcohol or other sedative agents have been co-ingested.

Management is supportive. Activated charcoal may be beneficial if given within one hour of ingestion. The level of consciousness can be improved by administration of the specific antagonist flumazenil, but this may be at the expense of adverse effects, including convulsions (especially in those with a history of seizures or co-ingesting proconvulsant agents) and acute withdrawal. Current guidelines in the UK suggest that flumazenil may be used for patients who would otherwise require intubation and ventilation provided there are no contra-indications. Small initial doses should be used by staff who have appropriate training. ${ }^{14}$

\section{Gamma hydroxybutyrate}

Gamma hydroxybutyrate (GHB) is an endogenous neurotransmitter and gamma aminobutyric acid (GABA) agonist originally developed as an anaesthetic agent. The related compounds gamma butyrolactone (GBL) and 1,4-butanediol (1,4-B) are prodrugs of GHB and have similar actions.

The principal clinical effects of these compounds are neurological and include headache, agitation, ataxia, progressive confusion and drowsiness, which are often associated with tremor and myoclonus. Nausea, vomiting and diarrhoea are also common. In severe cases, coma with reduced tendon reflexes and respiratory depression develop, especially if alcohol or other sedatives are involved. Bradycardia and hypotension, metabolic acidosis, electrolyte disturbances and hyperglycaemia may occur. ${ }^{15}$ Coma may be prolonged but with a characteristic abrupt recovery.

Treatment is supportive. Appropriate airway and respiratory management are essential.

\section{References}

1 National Statistics for Health and Social Care. Statistics on drug misuse, England, 2007. www.ic.nhs.uk/pubs/drugmisuse 07

2 Morgan O, Griffiths C, Toson B et al. Trends in deaths related to drug misuse in England and Wales, 1993-2004. Health Stat Q 2006;31:23-7.

3 Advisory Council on the Misuse of Drugs. The classification of cannabis under the Misuse of Drugs Act 1971. Available at: drugs.homeoffice.gov.uk/publicationsearch/acmd/cannabis-class-misuse-drugsact?view=Binary (last accessed 2 October 2007).

4 Treadwell SD, Robinson TG. Cocaine use and stroke. Postgrad Med J 2007;83:389-94.

5 Mokhlesi B, Leikin JB, Murray P, Corbridge TC. Adult toxicology in critical care. Part II: specific poisonings. Chest 2003;123:897-922.

6 Henry JA, Jeffreys KJ, Dawling S. Toxicity and deaths from 3,4-methylenedioxymethamphetamine ('ecstasy'). Lancet 1992; 340:384-7.

7 Hahn IH, Hoffman RS. Cocaine use and acute myocardial infarction. Emerg Med Clin North Am 2001;19:493-510.

8 Hollander JE. Cocaine-associated myocardial infarction. J R Soc Med 1996;89: 443-7.

9 Khan IA, Nair CK. Clinical, diagnostic, and management perspectives of aortic dissection. Chest 2002;122:311-28.

10 Gee P, Richardson S, Woltersdorf W, Moore G. Toxic effects of BZP-based herbal party 
pills in humans: a prospective study in Christchurch, New Zealand. N Z Med J 2005;118:U1784.

11 Wood DM, Dargan PI, Button J et al. Collapse, reported seizure - and an unexpected pill. Lancet 2007;369:1490.

12 Sporer KA. Acute heroin overdose. Ann Intern Med 1999;130:584-90.

13 Justo D, Gal-Oz A, Paran Y, Goldin Y, Zeltser D. Methadone-associated torsades de pointes (polymorphic ventricular tachycardia) in opioid-dependent patients. Addiction 2006;101:1333-8.
14 National Collaborating Centre for Mental Health. The short-term physical and psychological management and secondary prevention of self-harm in primary and secondary care. Leicester, London: British Psychological Society, Royal College of Psychiatrists, 2004. www.bps.org.uk/ downloadfile.cfm?file_uuid $=$ C11587F17E96-C67F-DD13-357E1AA3B75D\&ext $=$ pdf (last accessed 2 October 2007)

15 Caldicott DG, Chow FY, Burns BJ, Felgate PD, Byard RW. Fatalities associated with the use of gamma-hydroxybutyrate and its analogues in Australasia. Med J Aust 2004; 181:310-3. 